\title{
Deformity correction (upper tibial bone defect due to osteomyelitis) in lower limb using llizarov technique
}

\section{Abstract}

Here we are presenting a massive bone defect of upper tibia and $7 \mathrm{~cm}$ limb length discrepancy due to long standing osteomyelitis, which was treated successfully using Ilizarov technique and frame.

Keywords: non-union, deformity, osteomyelitis, Ilizarov
Volume 12 Issue 5 - 2020

\section{Bari MM,' Islam Shahidul, ${ }^{2}$ Bari AM Shayan $\mathrm{R}^{3}$ \\ 'Chief Consultant, Bari-llizarov Orthopaedic Centre,Visiting and Honored Prof, Russian Ilizarov Scientific Centre, Russia \\ ${ }^{2}$ Professor, Bari-llizarov Orthopaedic Centre, Bangladesh \\ ${ }^{3}$ Medical officer, Bari-llizarov Orthopaedic Centre, Bangladesh}

Correspondence: Mofakhkharul Bari, Chief Consultant, Bari-llizarov Orthopaedic Centre,Visiting and Honored Professor, Russian llizarov Scientific Centre, Kurgan, Bari-llizarov Orthopaedic Centre, I/I, Block\#E,SuvastuShirazi Square, Lalmatia, Dhaka- 1207, Bangladesh, Tel +88 01819211595 , Email bari.ilizarov3।@gmail.com

Received: October 12, 2020 | Published: October 30, 2020

\section{Brief clinical history}

A 21 years old female suffered from osteomyelitis of the left Tibia at the age of 7 and underwent 4 operations up to the age of 12 . At 17 years she experienced severe left knee pain with limping gait while walking without any prior event and was referred to Bari-Ilizarov Orthopaedic Centre for treatment.

\section{Preoperative clinical photos and radiographs (Figures I-7)}

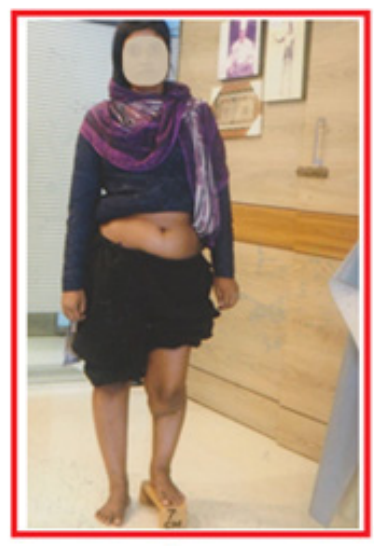

A

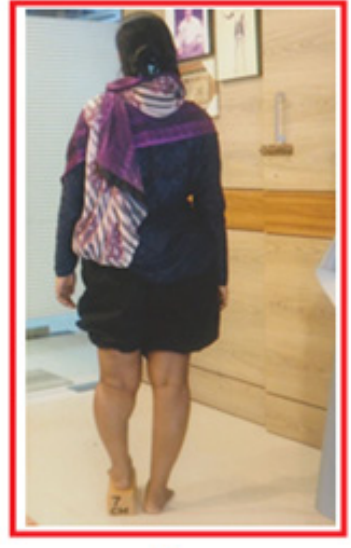

B

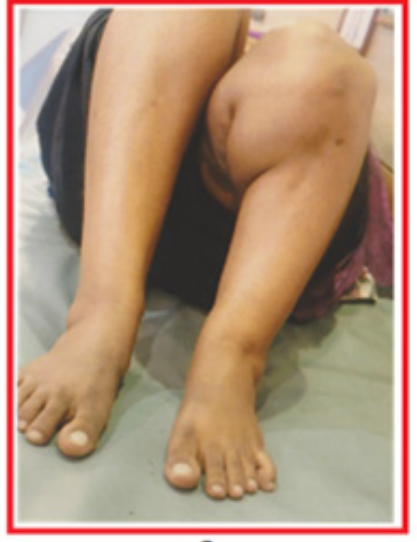

c

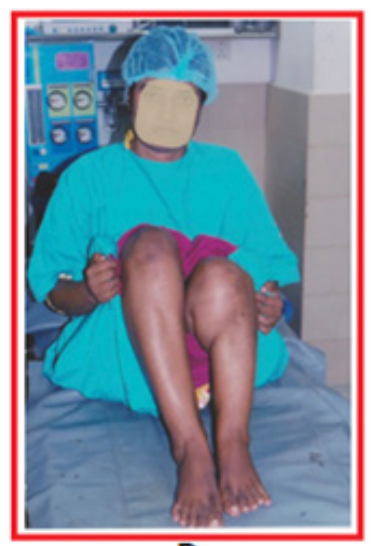

D

Figure I Preoperative clinical photos.

\section{Pre-operative problem list}

a. Massive bone defect.

b. $7 \mathrm{~cm}$. limb length discrepancy.

c. Deformity.

\section{Treatment strategy}

Two or three steps surgery is sometimes needed for deformity correction and limb lengthening using Ilizarov technique, which is a fantastic tool for this kind of difficult deformities. ${ }^{1-5}$

Step 1: Deformity correction and limb lengthening using Ilizarov technique of distraction histoneogenesis.

Step 2: Osteotomy of fibular true apex deformity and migrated proximal part is pulled down and fixed with olive wire.

Step 3: Two level corticotomy and lengthening of tibia and to achieve union in the proximal tibia.

Step 4: No bone graft is needed. 


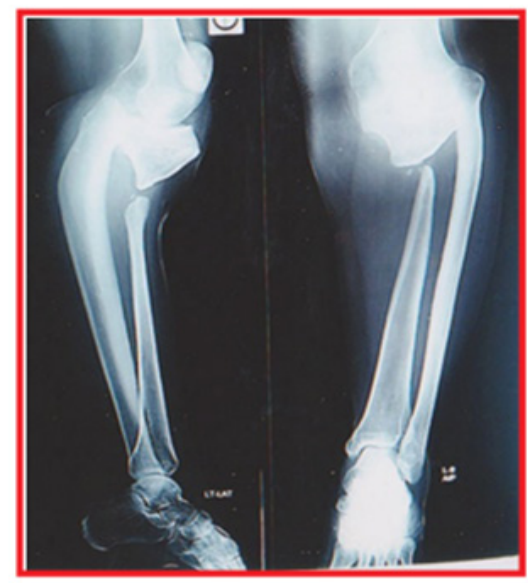

A

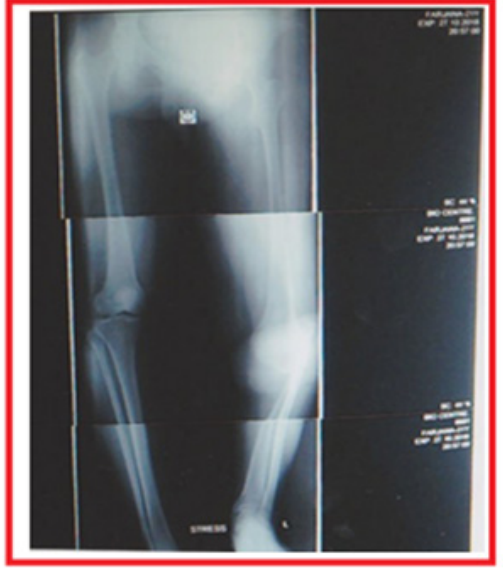

B

Figure 2 Preoperative radiographs.

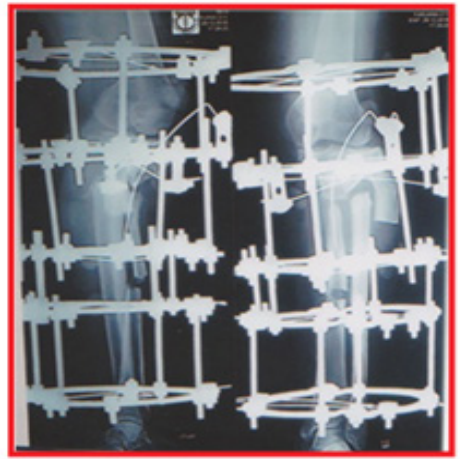

A

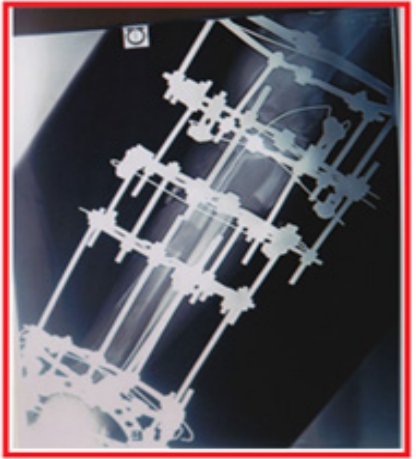

B

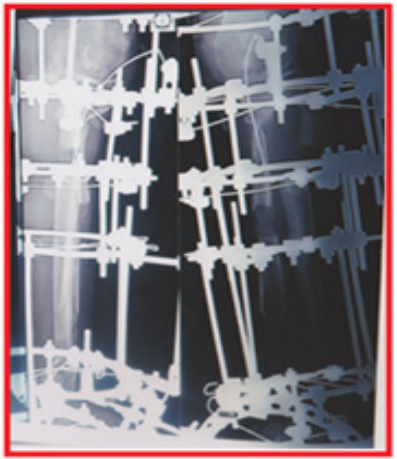

C

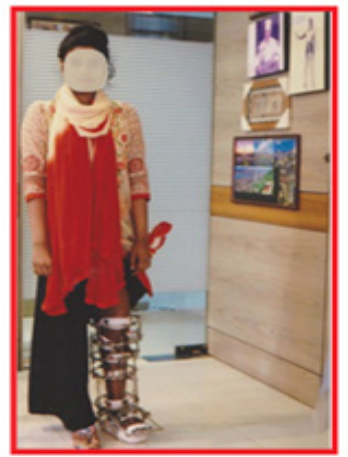

D

Figure 3 Placement of llizarov frame.

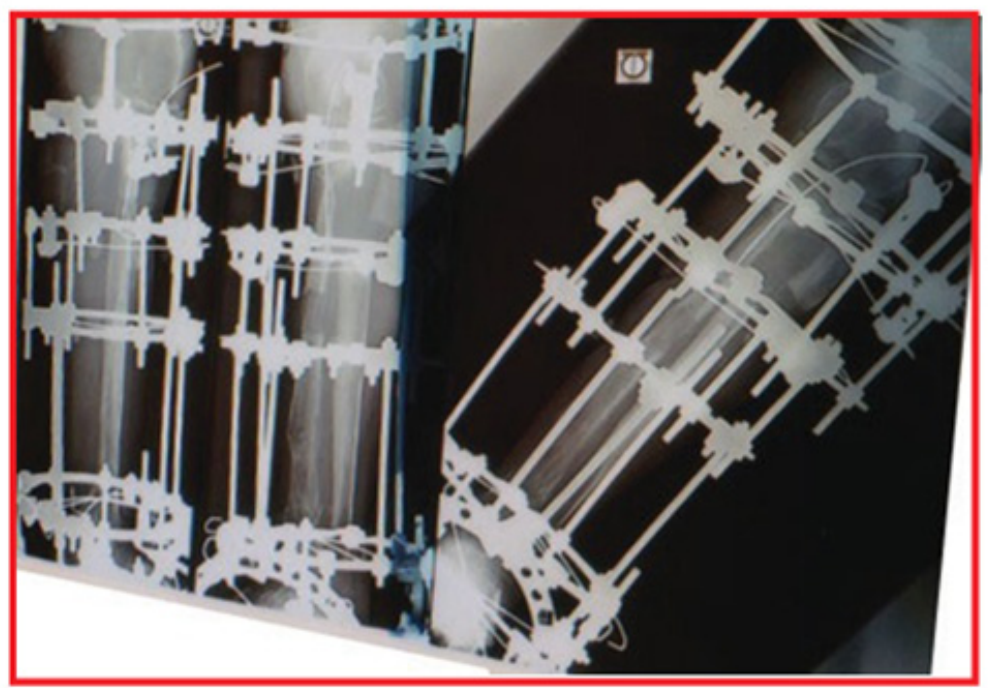

A

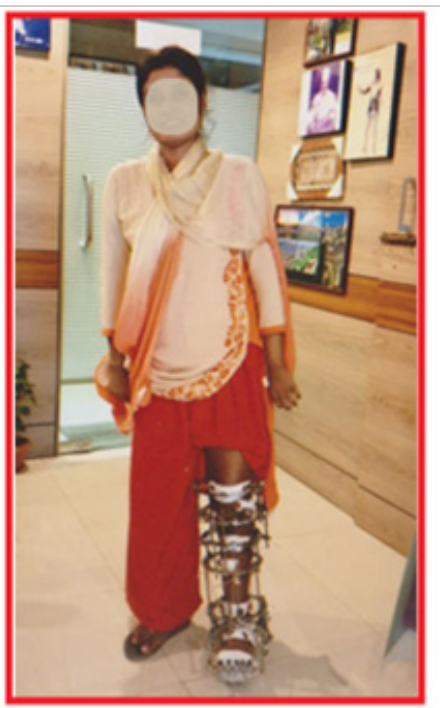

B

Figure 4 After deformity correction and lengthening of tibia at 2 levels. 


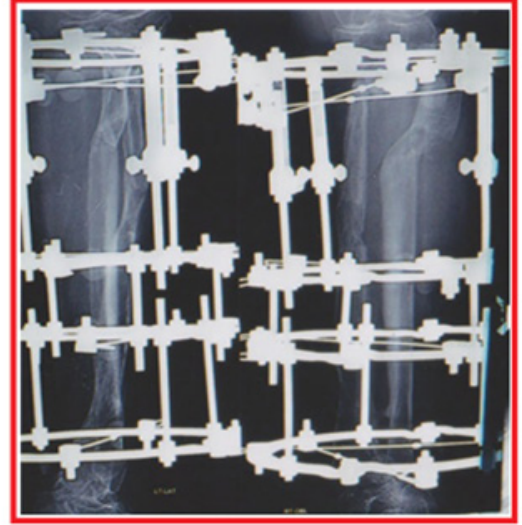

A

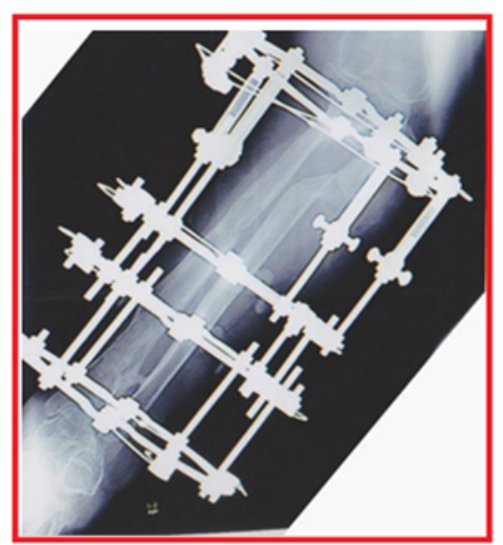

B

Figure 5 Radiograph of corrected tibial gap and deformity with full consolidation and llizarov apparatus in situ.

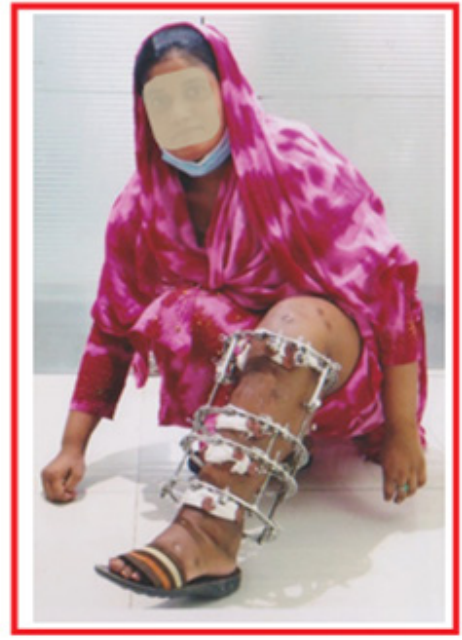

A

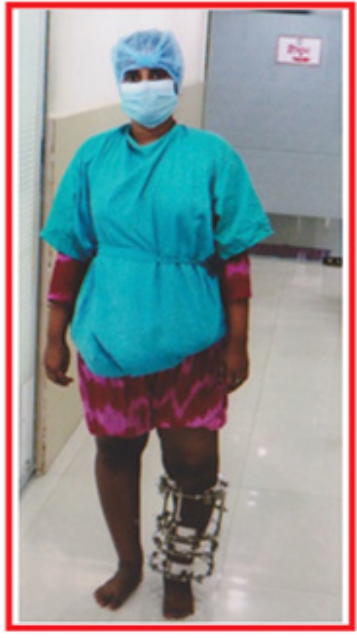

B

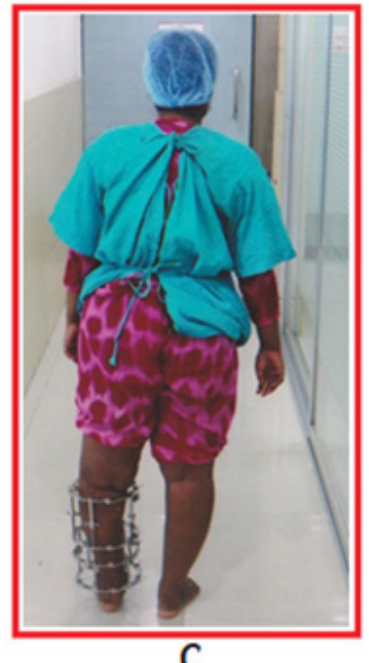

C

Figure 6 Before dismounting the llizarov frame, patient is in smiling mood in COVID-19.

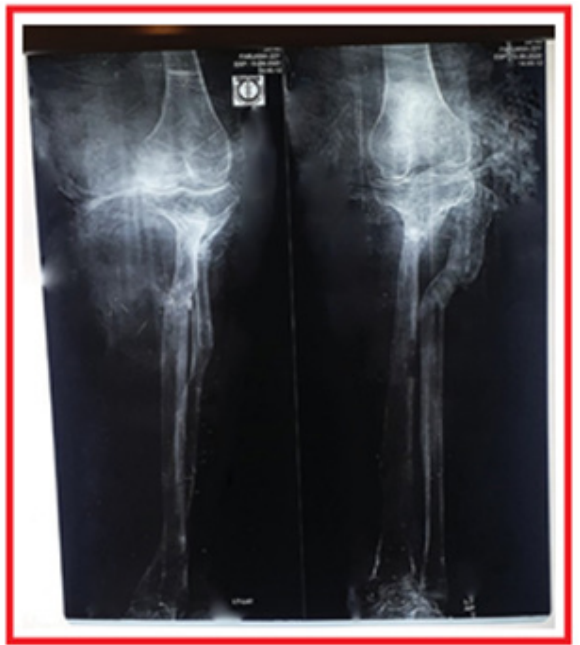

A

Figure 7 Final Radiograph after removal of the frame of tibia fibula with full correction of the deformity and non-union.

\section{Ilizarov'sprinciples}

Slow and steady traction on a living tissue creates a stress and which is metabolically activated and which stimulates histoneogenesis. Hypertrophic migrated fibula is osteotomized in the true apex of the deformity and proximal part is pulled down and is fixed with olive wire and with small incision nonunion site is opened and a guide wire is introduced in between the two fragments to maintain the alignment and axis. Two level corticotomy is done to achieve union and lengthening. ${ }^{6-10}$

\section{Avoiding and managing problems}

Massive bone defect, LLD and deformity can be simultaneously corrected by Ilizarov technique. To avoid any problems, Ilizarov ring construction should be planned elaborately and cautiously before performing the surgical intervention.

\section{Acknowledgments}

None. 


\section{Conflicts of interest}

The authors declare there are no conflicts of interest.

\section{Funding}

None.

\section{References}

1. Ilizarov GA. Transosseous Osteosynthesis theoretical and clinical aspects of the regeneration and growth of tissue. Germany: SpringerVerlag Berlin Heidelberg; 1992:512-526.

2. Bari MM. A color atlas technique of limb lengthening, surgical reconstruction and deformity correction by Ilizarov. Switzerland: Springer International Publishing; 2013:139.

3. Bari MM. Correction of leg deformities and Restoration of Function of leg bones by Ilizarov Technique. USA: MedCrave Publishing; 2014:93.

4. Bari MM, Shahidul I, Shayan BAMR. Tibialization of fibula for reconstruction of big tibial defects (post-traumatic, post-infective) by Ilizarov technique. MOJ Orthop Rheumatol. 2020;12(4):73-78
5. Ilizarov Svetlana, Rozbruch Robert S. Limb Lengthening and Reconstructive Surgery. JB \& JS. 2007:213-215.

6. Abdel-Aal AM. Ilizarov bone transport for massive tibial defects. Orthopedics. 2006;29:70-74.

7. Catagni M. Treatment of massive tibial bone loss due to chronic draining osteomyelitis: fibula transport using the Ilizarov frame. Orthopedics. 2007;30(8):608-611.

8. Shaft R, Fragomen AT, Rozbruch SR. Ipsilateral fibular transport using Ilizarov-Taylor spatial frame for a limb salvage reconstruction: a case report. HSS J. 2009;5(1):31-39.

9. Agiza AR. Treatment of tibial osteomyelitic defects and infected tibial pseudarthroses by the Huntington fibular transference operation. $J$ Bone Joint Surg Am. 1981;63(5):814-819.

10. Takami H, Takahashi S, Ando M, et al. Vascularized fibular grafts for the reconstruction of segmental tibial bone defects. Acta Orthop Trauma Surg. 1997;116(6-7):404-407. 